\title{
Construction of the Application Systems for Universal Education in Architectural Heritage - Multimedia Touch Screen Desk System
}

\author{
SATO. Reika ${ }^{1,2, a}$, GUO Weimin ${ }^{2}$ \\ ${ }^{1}$ Department of Design, Jiang Nan University, 214122, China \\ ${ }^{2}$ Department of Digital Games, Osaka Electro-Communication University, 575-0063, Japan
}

\begin{abstract}
The importance of popular education in architectural heritage is well known. It is an effective method for public education to develop applications that utilize digital copy of architectural heritage. We provide a case study focusing on the historical buildings of Toji Temple in Kyoto, Japan. We digitize the historical buildings in both overall construction and detailed structures. We build a demonstration and operating system using multimedia technologies such as multimedia touch screen desk system. The system will produce 3D digital models of architectural heritage with high resolution and use advanced technology to develop a variety of demonstration applications that can enhance your presentation and ease operation. The users can also have more opportunities and ways to improve their interests in learning and understanding about the architectural heritage knowledge, hence finding new ways to further improve the methodology of architectural heritage education with the application of multimedia interactive technologies and digital copy of historical buildings.
\end{abstract}

\section{Introduction}

Many countries attach great importance to conservation and education of cultural heritages in a city, a key part of which is architectural heritage. Architecture represents historical legacy for the modern society, telling stories of a nation's cultural development and transmitting various national development information. However, over time, many architectural heritages have disappeared or are disappearing, rendering conservation of these heritages so challenging a task in the modern development process. Popular education of architectural heritages becomes imminent, so that their history and charm can be learned and felt. Hard efforts must be made to discover the historical and cultural messages in the architectures so as to build awareness and energy for heritage conservation.

Digital copy of architectural heritage matters first in that it can visualize and present architectural research assumptions and results of vanished buildings. The digital copy is preserved and accessed as cultural heritage, and the non-visual (lost or non-public, unsplit, inaccessible, etc.) parts get visualized at the same time. In other words, the heritage is made more accessible and digestible, arousing greater interest to learn in the public.

Conservation of existing architectural heritages in itself contradicts with their exposure to public. Restoration and preservation efforts can be offset by long-time exposure and demonstration of the buildings. In contrast, demonstration of their digital copy is vivid, and free from constraints of location, time and space, thus more interesting, practicable and digestible. From the perspective of digital copy production, it's easier to

\footnotetext{
alihua@mwd.biglobe.ne.jp
}

produce, process and refine the contents to be demonstrated; transmission means is not constrained by location or time; and online promotion and education can reach more people.

In recent years, the touch screen technology is growing increasingly popular. Intuitive and fast in operation, it has been applied to home appliances, game consoles and mechanical equipment. Yet, large-scale application of this technology is no easy. As its alternative, the projector-based multi-media touch screen system, with a large display screen and touch-enabled, comes into being. The large screen reacts to touch based on the detecting function of the infrared radar.

Virtual reality technology can digitize architectural heritages. And with interactivity, optional viewpoints, optional dimensions, audio guide and other functions, it can better play its role in the popularization of architectural heritage. This technology comes down to computer graphics processing, human-computer interaction technology, sensor technology, artificial intelligence, etc. With this technology, viewers can be guided into virtual space for detailed observation and leaning, thus leading to better results in the popular education.

Kyoto is historically and culturally icon citie in Japan's development. This paper studies Toji Temple in Kyoto, so as to explore new approaches to copy and popularize architectural heritage via multimedia interactive technologies.

Toji Temple was built in the Heian period, with a history of over 1,200 years. It is a representative cluster of Buddhist architecture, and became a UNESCO world 
heritage site in 1994. This historical building was burnt, and rebuilt and restored. Now they represent a key part in Japan's popular education of architectural heritage.

\section{Construction Of The Multimedia Touch Screen Desk System For Toji Temple In Kyoto}

Toji Temple was originally built in Heiankyo as Kyō-ōgokoku-ji which indicates that it previously functioned as a temple providing protection for the nation, and then was given as a present by Emperor Saga to priest Kobo. There the Shingon sect of Buddhism introduced from China was lectured. The architecture comprises the Kondo Hall, Kodo Hall (existing lecture hall as is shown in Figure 1), shokudo Hall, Toji Pagoda, Mieido House and other buildings. Based on the 3DCG modeling technology, both the entire appearance of the architecture and its detailed structure are presented as in Figure 2 and Figure 3 respectively.

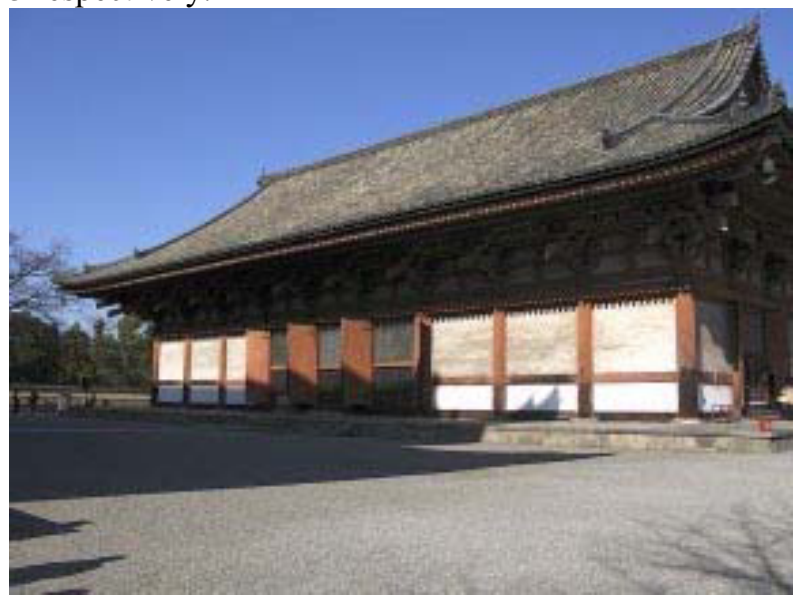

Figure 1. Kodo Hall in Toji Temple



Figure2. Modeling of the Kodo Hall

The importance of popular education in architectural heritage is well known. It is an effective method for public education to develop applications that utilize digital copy of architectural heritage. We provide a case study focusing on the historical buildings of Toji Temple in Kyoto, Japan. We digitize the historical buildings in both overall construction and detailed structures. We build a demonstration and operating system using multimedia technologies such as multimedia touch screen desk system. The system will produce $3 \mathrm{D}$ digital models of architectural heritage with high resolution and use advanced technology to develop a variety of demonstration applications that can enhance your presentation and ease operation. The users can also have more opportunities and ways to improve their interests in learning and understanding about the architectural heritage knowledge, hence finding new ways to further improve the methodology of architectural heritage education with the application of multimedia interactive technologies and digital copy of historical buildings.

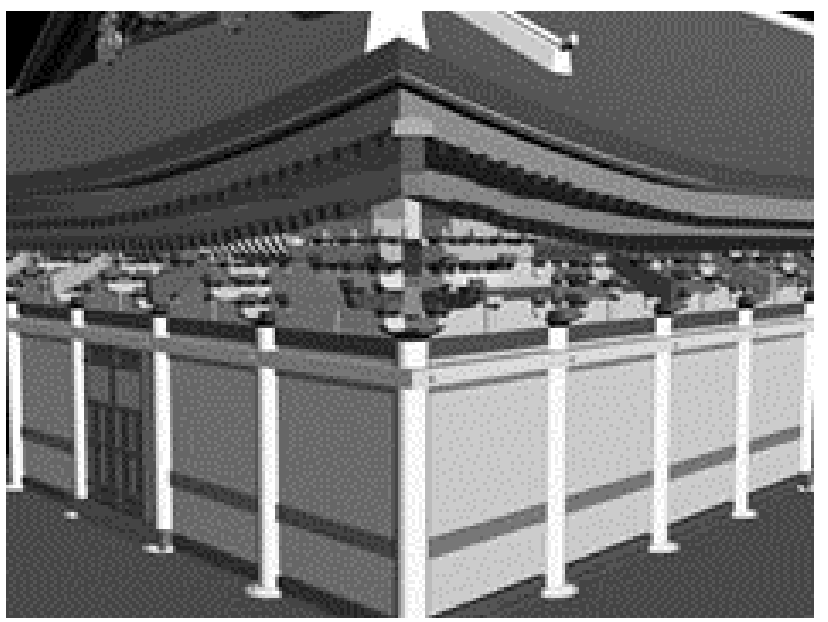

Figure3.Detailed Structure of the Architecture

To enable interactive operation on a large touch screen with the copied 3D architecture, the multimedia touch screen desk system is designed and developed. As is shown in Figure 4, this system comprises an 80-inch frosted glass desktop, a projector with ultra-short focus and near-infrared radars.

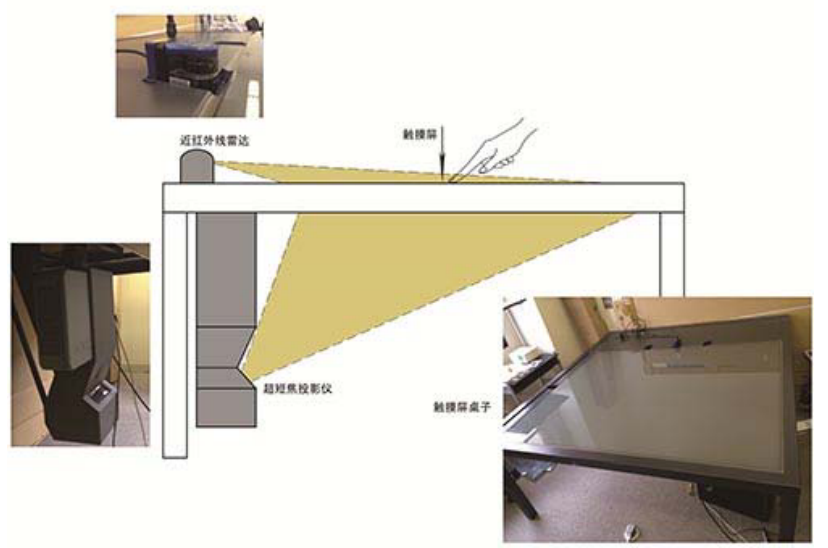

Figure 4. Components of the Multimedia Touch Screen Desk System

\subsection{Desk-type touch screen}

In the newly developed desk-type multimedia touch screen system, there is an 80-inch frosted glass desktop (a square with side length of $186 \mathrm{~cm}$ ); beneath the desktop an ultra-short focused projector (Sanyo LP-XL51) is installed to project images onto the glass desktop; and at the sides of the desktop, near-infrared radars are built in to scan and detect touch spots on the desktop. To prevent vibration from touch, the desk is made of heavy stainless steel. For the convenience of operation, the display screen desk and the projector are integrated. And in case that the 
80-inch large touch screen would bend because of the dead weight, the desktop is made of $10 \mathrm{~mm}$-thick frosted glass. Four desk legs can be removable, and the height of the desk is $75 \mathrm{~cm}$, rendering it convenient to operate the system in a standing position, as is shown in Figure 5. Grooves are built along the four outer sides of the desktop to store near-infrared radars, enabling the installation of four radars at most for touch spot location. Because of those multiple radars, several layers of touch surface are combined, so that no blind angles would be missed and the detection accuracy would increase.

\subsection{Near-infrared radar}

Currently, many projector-based touch screen applications feature infrared camera detection of touch spots, and different infrared-relied systems have different strengths[1]. When an infrared radar is used, anything movement, not limited to finger touch, can be detected. So it also can project images to the floor or the wall. On top of the desktop use, adjustment of the projector's focal length enables floor or wall use. Then radars are responsible for tracing footsteps or other mobile objects in contact with the ground or wall. Radars can also detect multiple touch spots simultaneously, which means the system can be operated by several people at the same moment. In addition, radars are capable of identifying the shape of the target object, and based on this function, additional signals can be sent by touch. But the infrared radar has its disadvantage. It cannot detect the range behind itself. So in the development of the touch screen desk system, the operation range must be taken fully into consideration.

With high-speed beam scanning, near-infrared radars are able to identify touch spots on the desktop. To capture touch spots, the radar-based range measuring device incorporates UBG-04LX-F01 range sensors produced by Hokuyo. The radar has a view angle of 240 degrees and can finish one beam scanning in 28 microseconds, capable of detecting touch spots in various shapes. Assume that one touches the desktop $1 \mathrm{~m}$ away from the radar, the beam scanning distance would be $6 \mathrm{~mm}$, so any touch spot of more than $6 \mathrm{~mm}$ radius can be located.

Touch signals received by sensors as is shown in Figure 5 are in various shapes: (1) for one finger, (2) for two fingers, (3) for a palm and (4) for a fist. After the touch stays at the screen for over 28 microseconds, the touch spot will be detected[2].



Figure5. Data Mapping of the Touch Spots Detected by Nearinfrared Radars

Radars can detect touch made by objects substantially isotropic with radar beams, which can be a finger, a pointing stick, a chessman or other objects. Glass objects that can be pierced by radar beams or objects with mirrors that can reflect beams are not applicable. Any item used for touching is equivalent to a mouse delivering a detection point, so multiple items can be used simultaneously for giving various detection points. The scanning plane of radars must be accurately above the touch screen. The distance between the two surfaces is usually controlled within $5-10 \mathrm{~mm}$.

\subsection{Application of digitized Toji Temple buildings}

Use of the desk-type touch screen system in demonstrating Toji Temple buildings enriches the approaches to education of historical architectural heritage. In the demonstration to college students, this novel approach inspires their strong interest. And during college open days, the system catches the eyes of many children and elderly people, and is highly recognized.

\section{COMMENTS ON THE APPLICATION SYSTEMS}

It is a new try to apply the touch screen desk system in the education of architectural heritage. More applications need to be developed, and more technologies improved.

The touch screen desk system applies widely. It can demonstrate various documents, graphics and 3D representations. Participants can be one person or two to four people. The currently developed system realizes the demonstration of the copied buildings in Toji Temple. This system allows for both a bird's-eye view and a walking view of the architecture. Each part of the building can be zoomed in or out for detailed observation. Users can choose to view the heritage from their preferred height and angle, and within the preferred visual range. And when they use the near-infrared detection device, they will not experience inaccuracy or delayed response in detection.

Usually infrared detection-based touch screen systems only respond to warm human hands. In 
comparison, the near-infrared radar can detect touch spots but without the constraint of temperature. So projection and imaging can be done both on translucent glass or plastic plates, and on the ground or the wall, where touch spots can also be detected. In this sense, more projection screens are available.

When evaluated as a demonstrating screen, the touch screen desk system gets the highest score. In evaluation of its projection methods, the desktop screen and ground projection are both considered. In ground projection, a projector with a general focus length is used to project images onto the $5 * 5 \mathrm{~m}$ floor, and the near-infrared radars to detect user locations on the ground; and the user controls the architecture representation by walking. Demonstration through ground projection requires cooperative footsteps. This means more attention to the architecture itself will be diverted to walking control. In comparison, wall projection is more applicable to detailed introduction of architectures. The narrator touches the wall with a pointing stick, and similarly the near-infrared radars detect the touch spots to control the image-viewing process. This method is similar to general PC demonstrations via a mouse, where the specific experience of operating is absent.

The digital copy of architectural heritage is visualized representation, just as drawings and photos. The difference is that it allows users to walk in virtual realistic space, free from the constraint of angle, scale and time. Based on the survey results, users have different observation focuses when operating the system from looking at photos shown in Table 1. This may lead to many new findings.

Table 1. Survey Results and Comparison

\begin{tabular}{|c|c|c|}
\hline $\begin{array}{l}\text { Observati } \\
\text { on Focus }\end{array}$ & Observer Interpretation & $\begin{array}{c}\text { Compared } \\
\text { with Looking } \\
\text { at Photos }\end{array}$ \\
\hline $\begin{array}{l}\text { Location } \\
\text { and scale }\end{array}$ & $\begin{array}{l}\text { Observer 1: it's like you're in } \\
\text { real buildings. When you look } \\
\text { down at them, you'll get a } \\
\text { clear idea of how they're } \\
\text { arranged. } \\
\text { Observer 2: it's really like } \\
\text { being there if you follow } \\
\text { those moving lines. } \\
\text { Observer 3: so large } \\
\text { buildings! But not far from } \\
\text { each other. }\end{array}$ & $\begin{array}{l}\text { More detailed; } \\
\text { (Observer) } \\
\text { imagining } \\
\text { himself/hersel } \\
\text { f in the real } \\
\text { building, and } \\
\text { wishing to see } \\
\text { more clearly }\end{array}$ \\
\hline $\begin{array}{l}\text { Appearan } \\
\text { ce }\end{array}$ & $\begin{array}{l}\text { Observer 1: people built so } \\
\text { delicate buildings even } \\
\text { hundreds of years ago! } \\
\text { Observer 2: tiles on the roof } \\
\text { are very beautiful. And Eaves } \\
\text { that large must be very } \\
\text { effective in blocking lights. } \\
\text { Observer 3: those small } \\
\text { sculptures on top of the roof } \\
\text { have any special meaning? } \\
\text { Doors are really high! }\end{array}$ & \\
\hline
\end{tabular}

Judging from the above comments on the demonstration method, virtual reality works are apparently more effective in inspiring users to see more and see into details. Stronger interest in architecture matters greatly in education. This is where the new operation method -- touch screen desk system stands out with its obviously stronger appeal for users.

In the production of a virtualized Toji Temple, the virtual reality technology is applied for delivering a more detailed copy of one of the buildings, the Toji Pagoda. The copy can represent every plane and section of the building, with introductory texts incorporated for each part and component. But the detailed production leads to a rather huge data file, making it slightly difficult to use touch screen for demonstration. A more appropriate demonstration method needs to be developed.

\section{Summary and outlook}

Thanks to the concerted efforts made by local administrative authorities, enterprises, research institutes and colleges and universities, many cultural heritage education and research centers have been established as part of the three-in-one programs combining business, education and research. These centers are where citizens learn about cultural heritages. There exhibits real heritage pieces and reference material with new demonstration devices and methods. Routine activities are open to citizens and sometimes organized specially for primary and secondary school students, which prove very successful. At many of those activities, the two systems built by this study also play their part. In the future, the study will focus on following the rapid progress of computer technologies and developing various new application systems to provide meaningful backup for educational activities. Meanwhile, the existing applications should be further improved, and more relevant data collected for more efficient education. This study analyzes the popular education of Japan's two representative historical buildings, and the methods employed and results achieved can be reference for other countries and regions.

\section{References}

1. J.Han. Low-cost multi-touch sensing through frustrated total internal refection, ACM UIST, 2005, 115118.

2. T.Takami,etc. Design of the Multi-Touch Table with Near-Infrared Radars and its Application of Floor/Wall Display DiGRA JAPAN Game Studies, 2009,(1)26 30. 